\title{
Note asupra unor realizări ale obiectului direct în limba veche
}

\author{
Irina Nicula Paraschiv* \\ Institutul de Lingvistică „Iorgu Iordan - Al. Rosetti”, Calea 13 Septembrie 13, 050711 București, România \\ Facultatea de Litere, Universitatea din București, Str. Edgar Quinet 5-7, 010017 București, România
}

\section{Despre articol}

Istoric:

Primit 22 mai 2017

Acceptat 25 iunie 2017

Publicat 30 septembrie 2017

Cuvinte-cheie:

obiect direct

nearticulat (nedeterminat)

specific

non-specific

marcarea cu $p(r) e$

\begin{abstract}
Rezumat
Scopul acestui articol este de a analiza anumite construcții cu obiect direct realizat prin nume personal sau animat în limba română veche pentru a evidenția unele particularități de construcție, care fie nu s-au păstrat, fie au fost restrînse considerabil în limba modernă. Semnalăm, pe de o parte, tiparul cu obiect direct nedeterminat, care se înregistrează destul de extins în contextul unei clase mai largi de regenți decît în limba actuală și, pe de altă parte, variația în marcarea prin $p(r) e$ a expresiilor nominale personale, cu citire specifică sau nonspecifică, precum și între singular și pluralul generic obiect direct (pre sărac(ul) vs pre săraci/săracii).
\end{abstract}

\section{Introducere}

Comportamentul sintactic al obiectului direct în textele de limbă veche (secolul al XVI-lea - secolul al XVIII-lea) nu prezintă diferențe semnificative față de limba modernă. În sens larg, principalele fenomene pentru care se constată variații, investigate extins în lucrări precedente, sînt marcarea prin $p(r)$ e și condițiile de dublare clitică (Guruianu, 2005, p. 91-120; Tigău, 2011; Nicula Paraschiv, 2016, p. 123-143).

Contribuția prezentă nu este o analiză de detaliu, ci o privire de ansamblu asupra anumitor structuri cu obiect direct în limba veche. Vom discuta unele realizări „speciale” în textele de limbă veche-contextele cu expresii nedeterminate și cu expresii (non)specifice-și vom semnala rolul mărcii $p(r) e s ̧ i$ al determinării în interpretarea referențială (specifică) vs generică (nonspecifică) a obiectului direct.

Exemplele citate în lucrare sînt extrase din corpusul alcătuit în Institutul de Lingvistică „Iorgu Iordan - Al. Rosetti” al Academiei Române, care a fost utilizat pentru analizele asupra limbii române vechi.

\section{Asupra unor construcții cu obiect direct nedeterminat}

2.1. În limba actuală, nominalul obiect direct în poziție postverbală respectă anumite constrîngeri de definitudine, care se corelează cu trăsătura numărului (singular vs plural).

La singular, numele obiect direct cu referință concretă poate fi determinat definit sau indefinit (1). Ocurențele obiectului direct nedeterminat sînt limitate la anumite contexte determinate lexical [infra, (3)].

Contextele cu nominal indefinit (1a) prezintă o ambiguitate de analiză (existențială vs referențială; vezi și Farkas, 2013, p. 200): în interpretarea existențială, în propoziție se enunță existența unei cărți oarecare pe care locutorul urmează să o cumpere; în interpretarea referențială, locutorul se referă la o carte anume (locutorul atribuie o valoare specifică variabilei carte).

(1) a. Cumpăr o carte și revin.

b. Cumpăr cartea.

\footnotetext{
*Adresă de corespondență: irina_nicula@yahoo.com.
} 
Posibilitatea ca obiectul direct să se realizeze printr-un nominal nedeterminat cu referință concretă (2) este limitată la anumite clase de verbe [vezi $(2 \mathrm{a})$ vs $(2 \mathrm{~b}, 3)]$ :

(2) a. ${ }^{*}$ Cumpär carte.

b. Are casă.

Ocurența obiectului direct nedeterminat ${ }^{1}$ (nearticulat) este legitimată, la singular, în următoarele condiții (Copceag, 1964, p. 195-201; Dobrovie-Sorin, 2013, p. 68-70): (i) cu verbul a avea sau cu alte verbe de achiziție (3a); (ii) cu verbe intensionale precum a căuta, a angaja etc., care subordonează o eventuală viitoare posesie (3b); (iii) cu verbe ca a purta, a folosi etc., care subordonează semantic verbul de posesie a avea (3c); (iv) cu verbe „ușoare” ca a face, a ține, a lua etc. (3d); (v) în expresii idiomatice; vezi (3e), în care nominalul obiect direct este marcat diferențiat prin pe.

În numeroase situații, obiectul direct nedeterminat desemnează proprietăți.

(3) a. Are casă. / Primește pachet în fiecare săptămînă.

b. Caută casă. / Cere chitanță. / Angajăm bucătar. / Aștept telefon.

c. Port cascä. / Folosesc creion, nu stilou.

d. Fac curățenie. / Ia loc! / Ținem regim.

e. Cuipe cui se scoate.

La plural, distribuția obiectului direct nedeterminat este mai puțin constrînsă. Cele mai multe verbe tranzitive acceptă ca obiect direct atît substantive cu determinant indefinit sau definit, cît și substantive nedeterminate. Restricția apare în contextul unor verbe psihologice cu subiect Experimentator, care nu admit tiparul cu substantiv nedeterminat: (5a) vs (5b).

(4) a. Cumpăr niște cărți / cărțile / cărți.

b. Desenez nişte copaci / copacii / copaci.

c. Văd niște filme / filmele / filme.

(5) a. *Respect doctori.

$v s$

b. Respect doctorii. / Îi respect pe doctori.

2.2. Spre deosebire de limba actuală, în limba veche, constrîngerile de articulare a numelui obiect direct sînt mai ezitante (Stan, 2013a, p. 298; vezi și 2013b, p. 175). Investigarea textelor vechi evidențiază faptul că există un tipar destul de extins cu nume numărabil nedeterminat, iar clasa lexicală a verbelor care permit acest tipar este mai largă decît cea din limba actuală [a fura, a omorî, a săruta, a tăia, a ucide etc.; vezi exemplele (6)-(7)]. În toate aceste construcții, singularele nedeterminate sînt interpretabile ca expresii nonspecifice (nonreferențiale).

Construcția cu obiect direct nedeterminat, caracteristică textelor legislative, este frecventă în traduceri (7), dar se înregistrează, mai rar, și în fragmentele originale (6). Trăsătura nedeterminării apare atît la numele nonanimate $(7 a-b)$, cît și la cele animate $(6,7 c-e)$ sau umane $(7 f-i)$, însoțite $(7 b, e, i)$ sau nu de modificatori $(6,7 \mathrm{a}, \mathrm{c}-\mathrm{d}, \mathrm{f}-\mathrm{h})$.

(6) cela ce fură dobitoc (...) Cine fură găină (CPrav.1560-2, $4^{\mathrm{r}}$, prefață)

(7) a. cela ce invață pre altul să margă să tae pom (Prav.1646, 42)

b. celuia ce-i vor därui lucru de furat (Prav.1646, 80)

c. cela ce va fura cal sau bou (Prav.1646, 40)

d. văcariul ce va lua dobitoc să-l pască (Prav.1646,41)

${ }^{1}$ Distribuția limitată a singularelor nedeterminate este un argument în favoarea intepretării acestora, de către unii cercetători, nu ca expresii argumentale canonice, ci ca modificatori ai predicației verbale (vezi și Farkas, 2013, p. 68). 
e. cela ce va omorî dulău de turmă (Prav.1646, 41)

f. cela ce va săruta copil cu rîvne (Prav.1646, 143)

g. Cela ce va răpi călugăriță de la mănăstire (Prav.1652,257)

h. care arbiereu va opri vreun popă dă liturghie sau va afurisi mirean (Prav.1652, 90)

i. Oricine va ucide fur zioa sau noaptea (Prav.1652, 249)

Tiparele cu nedeterminare de mai sus (6)-(7) concurează cu cele în care numele este însoțit de un cuantificator $(8 a-c)$ sau de articolul indefinit:

(8) a. Dărîmînd neștine un copaci va scăpa săcurea și va ucide vreun dobitoc (Prav.1646, 41)

b. care preot va afurisi pe vreun creștin färă de leage (Prav.1652, 91)

c. și el va aduce niscare dobitoc, de-l va băga în țarină (Prav.1646, 60)

d. Cînd va merge neștine să aducă niște dobitoc den cîmp (Prav.1646, 206)

e. Dacă un văcar a ucis sau a ologit un bou (...) este vinovat (Prav.1646, 206)

Obiectul direct nedeterminat se actualizează și în construcții simetrice, în care nominalele, legate printr-o prepoziție (drept, pentru), au interpretare nonspecifică.

(9) a. acesta să dea vită drept vită (Prav.1646, 60)

b. să dea bou pentru bou și asin pentru asin și oaie pentru oaie (Prav.1646, 206)

Cu excepția tiparelor menționate mai sus, în exemplele din (3), limba română modernă nu conservă structurile cu obiect nedeterminat la singular, folosind curent pluralul generic (nedeterminat): a fura găini, a ucide hoți etc.

\section{Realizări ale obiectului direct. $P(r) e$ în marcarea obiectului direct (non)specific}

3.1. Marcarea prin $p(r) e$ a obiectului direct este un fenomen corelat cu trăsături precum caracterul uman sau animat al referentului și cu „proeminența epistemică” a acestuia (GALR, II, p. 396; Manoliu-Manea, 1993, p. 192-204; Pană Dindelegan, 2013, p. 128-135 și bibliografia).

Pentru limba actuală, $s$-au formulat constrîngeri de folosire a mărcii pe cu obiectul direct și s-a distins între condițiile de obligativitate vs opționalitate a mărcii. S-a arătat faptul că marcarea diferențiată a obiectului direct este o trăsătură scalară, în sensul în care, cu cît referentul obiectului direct se plasează mai sus în cadrul ierarhiei epistemice (nume nonpersonal < nume personal nonspecific nume propriu $<$ cuantificator universal < cuantificator personal < pronume demonstrativ sau personal $<$ nume care desemnează o persoană anume < nume de rudenie), cu atît este mai susceptibil să primească marca pe (pentru ierarhia „animatului”, v. Manoliu-Manea, 1993, p. 196-200; Pană Dindelegan, 2013, p. 130 și bibliografia).

Limitîndu-ne observațiile la construcțiile cu obiect direct realizat prin nume comune personale, menționăm contrastul dintre exemplele de la (10) și cele de la (11), în care prezența mărcii se asociază cu citirea referențială, în timp ce absența ei (11a-b) legitimează citirea „proprietate” („caut pe cineva / oricine care are calitatea de profesor”; „printre cunoștințele sale se numără și doctori”).
a. Îl caut pe profesor. ([+specific $])$
vs
b. Ii cunoaște pe doctori. ([+specific] $)$
a. Cautprofesor. ([-specific $])$
b. Cunoaște doctori. ([-specific $])$

Româna dispune totodată de posibilitatea de a utiliza nominalul obiect direct (singular și plural) nemarcat cu pe, atunci cînd este determinat definit. 
(12) a. Cautprofesorul.

b. Cunoaşte doctorii.

Niculescu (1965, p. 86-87) semnalează o diferență de sens între (10a) și (12a), respectiv (10b) și (12b), formulată în termeni de individualizare. Autorul observă că utilizarea mărcii este un semn al „concretizării individuale" a referentului, în timp ce absența ei, în contextul numelui definit, se asociază cu o proeminență epistemică mai scăzută. Astfel, într-un context precum îl caut pe profesor se presupune că alocutorul știe cine este profesorul pe care îl caută locutorul, pe cînd într-un exemplu precum caut profesorul, lectura este „caut un profesor anume, dar el nu este cunoscut locutorilor”.

Diferența de interpretare dintre cele două tipuri de structuri este determinată și de categoria semanticoreferențială a numelui obiect direct. Astfel, von Heusinger \& Chiriacescu (2013, p. 446) atrag atenția că, într-un exemplu ca (13), diferența de interpretare este cea dintre citirea referențială, individualizată (13b), și cea atributivă (de proprietate) (13a), menționînd că acest tip de contrast se asociază doar cu numele „funcționale” (primar, președinte, criminal etc.). În (13a) referentul este orice individ care se poate defini ca primar, în timp ce, în (13b), numele marcat cu pe nu se referă la funcția pe care o deține referentul, ci chiar la individul care ocupă această funcție.

\section{a. La inaugurarea aeroportului Braşov, cetățenii vor invita primarul. \\ b. La inaugurarea aeroportului Brașov, cetățenii îl vor invita pe primar.}

(apud von Heusinger \& Chiriacescu, 2013, p. 446)

În absența unui modificator al numelui obiect direct (14a) vs (14b), coocurența celor două mijloace de individualizare/specificitate (marcarea cu pe și determinantul) nu este admisă în limba română actuală decît în contextul numelor de rudenie cu referință unică (14c):

(14) a. *îl/îi caut pe profesorul / profesorii.

b. Il caut pe profesorul de chimie.

c. Ill sun pe tata / pe bunicul.

Atît structura cupe + nume nedeterminat, cît și construcția cu nume articulat pot avea, contextual, lectură nonspecifică, desemnînd un referent oarecare din categoria semantică corespunzătoare („orice copil care prezintă simptome de un anumit tip"):

\section{a. Dacă observați aceste simptome, îl luați pe copil și mergeți cu el la doctor. \\ b. Luați copilul și mergeți cu el la doctor.}

3.2. Pentru limba veche (secolele al XVI-lea - al XVIII-lea) s-a observat că, deși constrîngerile semantice și sintactice în utilizarea mărcii erau deja fixate la începutul perioadei menționate, fenomenul marcării continuă să prezinte oscilaţii pînă spre mijlocul secolului al XVII-lea (Tigău, 2011, p. 39-65; Stan, 2013b, p. 162-163; Nicula Paraschiv, 2016, p. 129-134). În dacoromâna veche, folosirea construcției marcate variază în funcție de tipul de text-original sau tradus—, dar și de caracteristicile lexico-semantice ale nominalului obiect direct. $S$-a constatat că, în textele vechi originale, utilizarea lui $p(r) e$ ca marcă specifică obiectului direct este foarte extinsă încă de la începutul perioadei delimitate (Guruianu, 2005, p. 95-103), în timp ce în textele traduse există variații mult mai mari și preferințe în funcție de trăsăturile sintactice și semantice ale obiectului direct (Tigău, 2011, p. 40; Nicula Paraschiv, 2016, p. 131-134; Stan, 2013b, p. 161-182).

În articolul de față ne vom limita la cîteva observații descriptive cu privire la construcțiile cu obiect direct nominal [+uman] / [+animat], pentru a semnala variația în ceea ce privește prezența sau absența mărcii $p(r) e$ și eventualele distincții cu care se corelează aceste fenomene.

În strînsă legătură cu utilizarea oscilantă a mărcii pre ca marcă a specificității, parcurgerea unor texte din limba veche evidențiază prezența unor construcții în concurență, care nu s-au conservat decît parțial 
în limba actuală. Ca trăsături particulare, se constată utilizarea extinsă a mărcii $p(r) e$ cu singularul generic (articulat sau nearticulat) ${ }^{2}$ și variația între singularul și pluralul generic (vezi observațiile cu privire la ezitările între articulare și nearticulare în contextul prepozițiilor din limba veche la Nedelcu, 2016, p. 430431).

(i) Se înregistrează variația între construcția cu pre + nume fără determinant și cea cu nume determinat definit, menținută şi în limba modernă în cazul unui număr restrîns de substantive, cum este cazul substantivului om „specia umană”:

(16) a. Dumnezen omul pre obrazul lui au facut (Po.1582,34)

b. Dumnedzău spală din lontru pre om de toate păcatele (șT.1644, 6)

c. Eu feciu pămîntul și omul pre dîns (DPar.1683, III/13 ${ }^{\mathrm{r}}$ )

d. Sărăciia pre om smereaște (DPar.1683, II/30v)

În limba veche, se identifică numeroase alte substantive care se angajează în această variație, în construcții cu interpretare nonspecifică:

(17) a. ceia ce ucig pre fur cînd îl vor prinde furînd (Prav.1646, 104)

b. nu poate nime să ucigă furul, cînd poate să-l leage și să-l ducă la giudeț (Prav.1646, 104)

c. Cela ce va sudui pre ucenic inaintea dascalu-său (Prav.1646, 154)

d. Dascălul ce-și va bate ucenicul nu să va certa (Prav.1646, 149)

e. Drept aceaia cu altfel de podoabă va veni cînd va judeca lumea (AD.1722-5, 101)

f. pre dînsul, drept aceia ascultați, iară nu pre lume (AD.1722-5, 13 ${ }^{\mathrm{v}}$ )

Obiectul direct nonspecific se realizează în limba veche și prin tipare cu substantivizare (recategorizare a unui adjectiv ca substantiv), cu sau fără pre:

(18) a. Ferice de care socoteaște pre mișel și calic. (DPar.1683, II/22 ${ }^{\mathrm{r}}$ )

b. Reapedele îmblî̀n>zeaște (...) iară neputinciosul mîngîie (CPrav.1560-2, $1^{\mathrm{v}}$ )

(ii) Spre deosebire de limba actuală, în limba veche, $p(r) e$ se înregistrează și în contexte cu obiect direct nonspecific realizat ca nume determinat definit la singular:

(19) a. Călugărul ce va fura pre egumenul, nu va avea certare (Prav.1646, 74)

b. Care vor să pîrască pre arhiereul, trebue să întreabe să afle ce oameni sînt și ce viață au (Prav.1652, 82)

c. Că în chipul lui Dumnădzău am făcut pre omul (DPar.1683, II/6

Se întîlnesc și structuri cu substantivizare (pre săracul < pre omul sărac) $(20 \mathrm{a}-\mathrm{b})$ sau cu elipsă a numelui (cel sărac < omul cel sărac) (20c-e) cu lectură nonspecifică:

(20) a. Cela ce clevetește pre measerul întărîtă pre cela ce l-au făcut pre îns (DPar.1683, III/ ${ }^{\mathrm{r}}$ )

b. Cela ce miluiaște pre săracul imprumuteadză lui Dumnădzău (DPar.1683, III/18 r)

c. Cela ce nu pune nevoință să socotească pre cel bolnav (Prav.1646, 100)

d. să-ndirepteadze pre cel dirept ce bine slujeaște a mulț (DPar.1683, III/44 ${ }^{\mathrm{r}}$ )

e. Ceia ce fac dirept pre cel strîmb (DPar.1683, II/17 ${ }^{\mathrm{r}}$ )

În structurile nonspecifice, numele (sau substantivizările) la singular (20) sînt în concurență cu numele/substantivizările la plural (21):

(21) a. Că-i va trînti Domnul pre necurațîi (DPar.1683, IV/56 ${ }^{\mathrm{r}}$ )

b. Și va aduna pre cei sfärîmaț (DPar.1683, III/29ª

\footnotetext{
${ }^{2}$ Vezi și observațiile din Niculescu (1965, p. 64-65), unde se precizează că trăsătura limbii de a accepta substantive nearticulate după prepoziție este specifică stadiilor vechi ale limbilor romanice. Caracteristica românei de a consolida această trăsătură în evoluția ulterioară este considerată de autor reflexul unui comportament arhaic al limbii.
} 
c. venit-au să mîntuiască pre cei robiț și pre cei rătăciţi $\left(\mathrm{AD} .1722-5,103^{\mathrm{v}}\right.$ )

(iii) În textele de limbă veche, $p(r) e$ este înregistrat și în contextul unui nume determinat definit [+uman] / [+animat], cu citire specifică (individualizată) (22a-f); Pană Dindelegan (2016, p. 83) motivează articularea formelor prin trăsătura unicităţii referentului desemnat de nume.

(22) a. Așa amu întrebă Hristosu pre orbulu $\left(\mathrm{CC}^{2} .1581,173\right)$

b. Atunce va munci pre sfătuitoriul să spue cu adevărat și să-l întreabe, sfătuitu-l-au au învăţatu-l-au să facă acea greșală (Prav.1652, 96)

c. Şi era atunci sîmbătă într-acea zi, cînd vendecă Domnul pre slăbitul (Ev.1642,398)

d. Şi trimisă pre corbul să vadză oare îndărăptat-au apa (DPar.1683, II/32 ${ }^{\mathrm{r}}$ )

e. va ucide pre bălaurul în dzua aceaea, pre acel din mare (DPar.1683, II/37 ${ }^{\mathrm{r}}$ )

f. Eu, Iisus am trimis pre îngerul să mărturisască voao aceastea la Beseareci (вв.1688, XXII, 932)

(iv) Atrag atenția și tiparele cu obiect direct nume de rudenie, care variază, pe de o parte, între marcarea $(23 \mathrm{a}-\mathrm{c})$ și nemarcarea cu $p(r) e(23 \mathrm{~d})$, și, pe de altă parte, între articularea definită și nedeterminare (23a); (23b) vs (23c), (24a) vs (24b).

(23) a. Ficiorulînțălept veseleaștepre tatăl, iară ficiorulnebun mîhneaște pre maică (DPar.1683, $\mathrm{II} / 30^{\mathrm{v}}$ )

b. Fiiul înțălept veseleaște pre tatăl, iară fiul fără crieri să strîmbă maică-sa (DPar.1683, III $/ 9^{\mathrm{r}}$ )

c. Tată și fecior nu iau pe bunică și strănepoată (Prav.1652, 787)

d. Legea oprește ca un bărbat să ia mamă și fată (Prav.1652,786)

(24) a. Și de ce am dezlegat pe tatăl și pe feciorul, adică le-am dat voie să ia mătuşă mică și nepoată? (Prav.1652, 787)

b. tată şi fecior nu iau pe mamă și pe fată (Prav.1652, 787)

\section{Concluzii}

Analiza descriptivă din acest articol evidențiază anumite particularități de construcție a obiectului direct nominal în limba veche.

(a) Se constată varietatea relativ mare a structurilor cu singulare numărabile nedeterminate; clasa regenților verbali care admit acest tip de construcție este mai bogată și nu se limitează la selecția semantică a numelor nonanimate [supra, (7)], așa cum se întîmplă în limba modernă [supra, (3)].

(b) Obiectul direct realizat prin nume personal prezintă o mare variație în construcție: marcat sau nemarcat prin $p(r)$ e (ucide pre fur / furul), articulat (fură pre egumenul) sau nearticulat (ucide fur); numele de rudenie obiect direct pot apărea marcate sau nemarcat cu $p(r) e$, articulate sau nearticulate, spre deosebire de limba actuală, unde este obligatorie coocurența mărcii $p e$ și a determinantului definit ( $p e$ mama, pe tata, pe bunica etc.).

Dintre tiparele identificate și inventariate în acest articol, unele sînt eliminate din limba modernă—cum este situația obiectului direct nonspecific realizat prin nume articulat [supra, exemplele din (19)]—, altele sînt mult restrînse [supra, (17)].

Ca trăsătură generală, se remarcă folosirea extinsă a construcțiilor cu singular nonspecific marcat cu $p(r)$ e (cela ce miluiește pre săracul), în locul cărora limba modernă preferă pluralul definit (săracii). 


\section{Bibliografie}

\section{A. Corpus}

AD.1722-5 = Antim Ivireanul, Didahii, în Opere, ed. G. Ștrempel, Editura Minerva, București, 1972.

вв.1688 = Biblia adecă Dumnezeiasca Scriptură a Vechiului și Noului Testament, tipărită întîia oară la 1688 în timpul lui Șerban Vodă Cantacuzino, Domnul Țării Românești, Editura Institutului Biblic, București, 1977.

$\mathrm{CC}^{2} .1581=$ Coresi, Cartea cu invățătură, ed. S. Pușcariu \& Al. Procopovici, Atelierele Grafice Socec, București, 1914.

CPrav.1560-2 = Coresi, Pravila, ed. Gh. Chivu, în I. Gheție (coord.), Texte românești din secolul al XVI-lea, Editura Academiei RSR, București, p. 218-231.

DPar.1683 = Dosoftei, Parimiile preste an, 1683, ed. M. Ungureanu, Editura Universității „Alexandru Ioan Cuza”, Iași, 2012. Ev.1642 = Evanghelie invvățătoare, Govora, ed. A.-M. Gherman, Editura Academiei, București, 2011.

Po.1582 = Palia de la Orăștie, ed. V. Pamfil, Editura Academiei Române, București, 1968.

Prav.1646 = Carte românească de învățătură, 1646, ed. A. Rădulescu, Editura Academiei, București, 1961, p. 33-106.

Prav.1652 = Indreptarea legii, 1652, ed. A. Rădulescu, Editura Academiei, București, 1962, p. 33-631.

ș.1644 = Şeapte taine a besearecii, 1644, ed. I. Mazilu, Editura Universității „Alexandru Ioan Cuza”, Iaşi, 2012, p. 173-259.

\section{B. Referințe}

Copceag, D. (1964). Un caso de omisión del artículo en rumano y en los idiomas iberrorromances, în „Revue roumaine de linguistique", vol. IX, nr. 2, p. 195-202 (republicat în Studii de lingvistică, Editura Clusium, București, 2005, p. 105-113).

Dobrovie-Sorin, C. (2013). Bare nouns, în Dobrovie-Sorin, C. \& Giurgea, I. (eds), A Reference Grammar of Romanian, vol. 1. The noun phrase, John Benjamins, Amsterdam/Philadelphia, p. 49-97, Crossref.

Farkas, D. F. (2013). The semantics of determiners, în Dobrovie-Sorin, C. \& Giurgea, I. (eds), A Reference Grammar of Romanian, vol. 1. The noun phrase, John Benjamins, Amsterdam/Philadelphia, p. 175-321, Crossref.

GALR = Guțu Romalo, V. (coord.) (2008). Gramatica limbii române, II. Enunțul, tiraj nou, revizuit, Editura Academiei Române, București.

Guruianu, V. (2005). Sintaxa textelor românești originale din secolul al XVI-lea. Sintaxa propoziției, Editura Universității din București, București.

von Heusinger, K. \& Chiriacescu, S. (2013). The discourse structuring potential of differential object marking. The case of indefinite and definite direct objects in Romanian, în „Revue roumaine de linguistique”, vol. LVIII, nr. 4, p. 439-456.

Manoliu-Manea, M. (1993). Gramatică, pragmasemantică şsi discurs, Editura Litera, București.

Nedelcu, I. (2016). Prepositions and prepositional phrases, în Pană Dindelegan, G. (ed.), The Syntax of Old Romanian, Oxford University Press, Oxford, p. 424-444, Crossref.

Nicula Paraschiv, I. (2016). The direct object, în Pană Dindelegan, G. (ed.), The Syntax of Old Romanian, Oxford University Press, Oxford, p. 123-149, Crossref.

Niculescu, Al. (1965). Individualitatea limbii române între limbile romanice, vol. I. Contribuții gramaticale, Editura Științifică, București.

Pană Dindelegan, G. (2013). The direct object, în Pană Dindelegan, G. (ed.), The Grammar of Romanian, Oxford University Press, Oxford, p. 125-148.

Pană Dindelegan, G. (2016). Gramatica „animatului” in limba română - cu raportare la limba veche, în „Limba română”, vol. LXIV, nr. 1, p. 74-92.

Stan, C. (2013a). The article and other determiners, în Pană Dindelegan, G. (ed.), The Syntax of Old Romanian, Oxford University Press, Oxford, p. 288-303, Crossref.

Stan, C. (2013b). O sintaxă diacronică a limbii române vechi, Editura Universității din București, București.

Tigău, A. (2011). The syntax and semantics of the direct object in Romance and Germanic Languages, Editura Universității din București, București. 